\title{
Lung consequences in adults born prematurely
}

\author{
Charlotte E Bolton, ${ }^{1,2}$ Andrew Bush, ${ }^{3,4}$ John R Hurst, ${ }^{5}$ Sailesh Kotecha, ${ }^{6}$ \\ Lorcan McGarvey ${ }^{7,8}$
}

\begin{abstract}
${ }^{1}$ Nottingham Respiratory Research Unit, School of Medicine, University of Nottingham, City Hospital Campus, Nottingham, UK ${ }^{2}$ Department of Respiratory Medicine, Nottingham University Hospitals Trust, Nottingham, UK

${ }^{3}$ Department of Paediatric Respirology, National Heart and Lung Institute, Imperial College, London, UK

${ }^{4}$ Department of Paediatric Respiratory Medicine, Royal Brompton Harefield NHS Foundation Trust, London, UK ${ }^{5}$ Department of Respiratory Medicine, Royal Free Campus, University College London, London, UK

${ }^{6}$ Department of Child Health, Cardiff University School of Medicine, Cardiff, UK ${ }^{7}$ Department of Respiratory Medicine, Centre for Infection and Immunity, Queen's University Belfast, UK ${ }^{8}$ Department of Respiratory Medicine, Royal Victoria Hospital, Belfast Health Social Care Trust, Belfast, UK
\end{abstract}

\section{Correspondence to Dr Charlotte E Bolton, Nottingham Respiratory Research Unit, School of Medicine, University of Nottingham, City Hospital Campus, Hucknall road, Nottingham NG5 1PB, UK; charlotte.bolton@nottingham. ac.uk}

Received 20 November 2014 Revised 18 February 2015 Accepted 6 March 2015 Published Online First 30 March 2015

\section{CrossMark}

To cite: Bolton CE, Bush A, Hurst JR, et al. Thorax 2015;70:574-580.

\section{ABSTRACT}

Although survival has improved significantly in recent years, prematurity remains a major cause of infant and childhood mortality and morbidity. Preterm births ( $<37$ weeks of gestation) account for $8 \%$ of live births representing $>50000$ live births each year in the UK. Preterm birth, irrespective of whether babies require neonatal intensive care, is associated with increased respiratory symptoms, partially reversible airflow obstruction and abnormal thoracic imaging in childhood and in young adulthood compared with those born at term. Having failed to reach their optimal peak lung function in early adulthood, there are as yet unsubstantiated concerns of accelerated lung function decline especially if exposed to noxious substances leading to chronic respiratory illness; even if the rate of decline in lung function is normal, the threshold for respiratory symptoms will be crossed early. Few adult respiratory physicians enquire about the neonatal period in their clinical practice. The management of these subjects in adulthood is largely evidence free. They are often labelled as asthmatic although the underlying mechanisms are likely to be very different. Smoking cessation, maintaining physical fitness, annual influenza immunisation and a general healthy lifestyle should be endorsed irrespective of any symptoms. There are a number of clinical and research priorities to maximise the quality of life and lung health in the longer term not least understanding the underlying mechanisms and optimising treatment, rather than extrapolating from other airway diseases.

Preterm delivery ( $<37$ weeks of gestation) accounts for $8 \%$ of UK births, and the proportion is increasing in many countries ${ }^{1}{ }^{2}$ Although survival of these infants has improved significantly with advances in obstetric and neonatal care, prematurity remains a major cause of infant and childhood mortality and morbidity. ${ }^{3-5}$ There is now a large population of adults who were born preterm, with current impairment in spirometry and increased susceptibility to respiratory infection, who constitute a significant public health and financial burden in terms of National Health Service healthcare provision. ${ }^{5-7}$

However, despite the numerical importance of the problem, it does not apparently impinge on the current practice of most adult chest physicians. ${ }^{8}$ The purpose of this article is to try to address this by highlighting how prematurity and its treatment impact long-term lung function and respiratory health; to discuss the implications for the treatment of obstructive airway disease in survivors of prematurity; and to highlight the gaps in knowledge that should be addressed by future research.

\section{Terminology}

- Extremely preterm: $\leq 28$ weeks' gestational age

- Very preterm: $\leq 32$ weeks' gestational age

- Late preterm: 33-36 weeks' gestational age

- Preterm: <37 weeks' gestational age

- Early term: 37-38 weeks' gestational age

\section{METHODS}

We conducted PubMed and MEDLINE searches using the terms <'bronchopulmonary dysplasia' or 'premature' or 'prematurity' or 'preterm'> AND <'follow up'> AND <'lung' or 'pulmonary' or 'airway' or 'respiratory' $>$, limiting to human and English-language manuscripts. We reviewed literature from our personal archives, and took relevant references and searched relevant articles for key references. Each author prepared the first draft of some parts of the manuscript. The entire manuscript was repeatedly reviewed by all authors until a consensus was reached.

\section{NORMAL LUNG DEVELOPMENT}

It is impossible to understand the developmental consequences of prematurity and its treatment and how this results in long-term disease without understanding normal lung development. Antenatal lung development has been reviewed in detail elsewhere. $^{9-12}$ Briefly, in the embryonic phase $(0-6$ weeks) the lung bud starts to differentiate from the primitive foregut and the main pulmonary arteries appear. In the pseudoglandular phase (7-16 weeks), the complete airway branching pattern is laid down, together with the pre-acinar vessels. The canalicular stage (16-26 weeks) is characterised by marked capillary multiplication, which establishes a loose three-dimensional network in the mesenchyme. There is flattening of the cuboidal cell layer and the first development of a thin air-blood barrier, with differentiation of type 1 and type 2 pneumocytes and the first appearance of surfactant. The saccular phase ( 27 weeks term) is followed by phase of alveolar development. These traditional anatomical stages have been shown to have accompanying gene expression patterns. ${ }^{13}$

Postnatally, the pattern of airway physiological development is best characterised by the global lung initiative (http://www.lungfunction.org/). The FVC and $\mathrm{FEV}_{1}$ increase throughout childhood to a plateau at 20-25 years. Meanwhile, the ratio $\left(\mathrm{FEV}_{1} / \mathrm{FVC}\right)$ decreases. ${ }^{14}$ Thereafter, there is a decline in both $\mathrm{FEV}_{1}$ and FVC into old age (figure 1). As a general rule, lung function is thought to track 


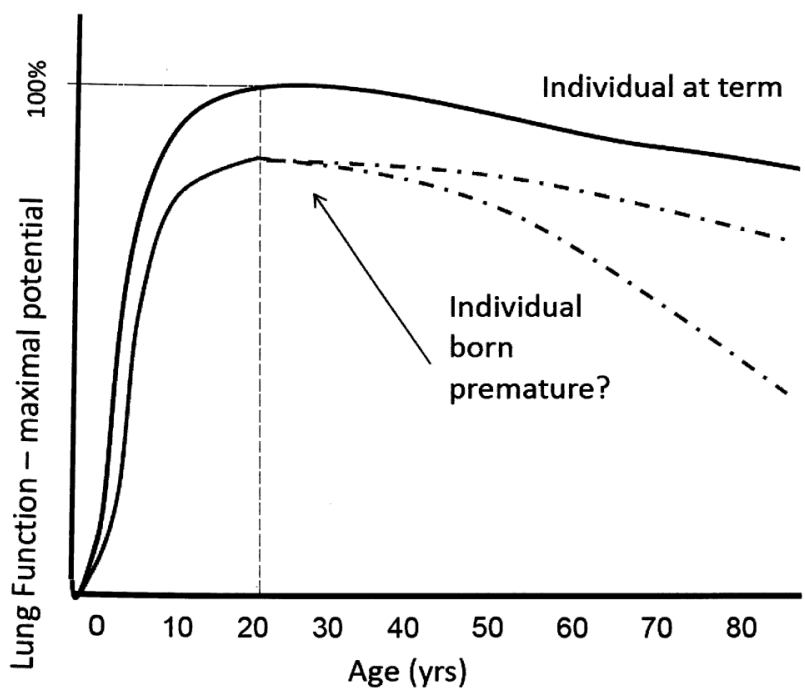

Figure 1 The life course of lung function. Black line indicates term individuals, grey solid line indicates preterm-born individuals and grey dashed line indicates possible rates of decline in lung function in preterm-born individuals.

throughout life, although under some circumstances there is potential for catch-up. ${ }^{15-20}$ The threshold for pathological airway obstruction may be crossed prematurely by any combination of (1) airway obstruction at birth, (2) failure to achieve normal airway growth in childhood and (3) accelerated decline in lung function.

Traditionally, alveolar numbers have been thought to be largely complete at age 2 years, thereafter with alveoli increasing in size. Recent in vivo studies using hyperpolarised 3-helium MRI suggest that alveolar numbers increase throughout the period of somatic growth, ${ }^{21}$ confirmed by direct histological measurements in rhesus monkeys. ${ }^{22}$ Hyperpolarised 3-helium MRI studies suggest that alveolar volume increases with ageing, ${ }^{23}$ particularly in the apices and mid-zones.

\section{PRETERM BIRTH AND LIKELY NEONATAL SCENARIOS}

Until recently most focus has been on preterm infants born at 32 weeks' gestation or less, especially if these infants required respiratory support with mechanical ventilation and increased ambient oxygen in the neonatal period due to neonatal respiratory distress syndrome (RDS). RDS results from failure to adequately expand the lungs after birth due to surfactant deficiency, which is especially relevant to preterm infants. Many of these infants progressed to prolonged supplemental oxygen dependency especially due to ventilator-induced and hyperoxic-induced acute lung injury of the fragile newborn lung. In 1967, Northway and colleagues first described the evolving clinical condition and associated pathological correlates of this lung injury and in the process coined the term bronchopulmonary dysplasia (BPD, often also called chronic lung disease of prematurity). ${ }^{24}$ Infants were more mature than the current preterm infant typically gestational ages of between 33 and 34 weeks and those who died from BPD had markedly fibrotic and atelectatic lungs.

With routine use of natural exogenous surfactant and antenatal maternal corticosteroids, together with gentler forms of mechanical ventilation (increasingly non-invasive use of CPAP ventilation), BPD is now largely confined to infants born at $<28$ weeks' gestation with the pulmonary process being more of dysregulated lung growth with decreased numbers of enlarged alveoli rather than the fibrotic processes previously observed. The term 'new' BPD is often used to describe these changes. Thus, the effects of prematurity and its treatment have changed over time, and may change again in the future; it should not be assumed that follow-up studies of young ex-preterm adults are necessarily relevant to the preterm deliveries of today. There have been various attempts to define BPD but of most prognostic value is supplemental oxygen dependency at and beyond 36 weeks' postconceptional age. ${ }^{25}$ More recently there have been attempts to define the severity of BPD on the basis of duration of oxygen dependency and any additional need for respiratory support. ${ }^{26}$ Admittedly, all these terms are crude, and more precise definitions of respiratory disease arising from prematurity are needed, preferably which predict outcome, but this is outwith the scope of this review.

There are several factors that may cause a premature birth and additionally likely to affect fetal lung development and adult outcomes; however, it is impossible to separate the causes from the neonatal consequences of prematurity. These include maternal smoking and chorioamnionitis. ${ }^{27} 28$ It is also becoming increasingly clear that even late preterm and early term delivery is associated with significant long-term morbidity. Another factor that can enhance airway obstruction is fetal growth restriction, which may be associated with preterm birth.

\section{FETAL PROGRAMMING}

The hypothesis that in utero events can reprogramme an individual for immediate adaptation to gestational disturbances but with deleterious consequences for later responses to adverse events, known as the Developmental Origins of Health and Disease hypothesis, has been studied in animal models in respiratory diseases. ${ }^{29}$ For example, in utero smoke exposure leads to enhanced responses to postnatal allergen and fungal exposure. ${ }^{30}$ In murine models, neonatal hyperoxia may affect adult cardiovascular function and lifespan ${ }^{31}$ and alter pulmonary oxidative stress and immune responses. ${ }^{32} 33$ The mechanism may be epigenetic, through DNA methylation. ${ }^{34} 35$ The most intriguing human data have come from a study of the responses to high-altitude hypoxia of adult survivors of persistent pulmonary hypertension of the newborn. ${ }^{36}$ Compared with 10 matched controls, the mean increase in pulmonary artery pressure at altitude measured by echocardiography at high altitude was significantly greater. There was no difference in the fall in arterial oxygen saturation. The relevance of this or any other effect of fetal programming and perinatal treatment in human survivors of prematurity is an important subject for future research. Whether similar abnormalities of the pulmonary arterial circulation persist in adult survivors of preterm birth is unknown, and it is speculative whether, if present, they may increase the risk of pulmonary hypertension if there is a second insult, for example, alveolar hypoxia at altitude.

\section{PRETERM BIRTH AND CHILDHOOD LUNG HEALTH}

In summary, the evidence below suggests that childhood survivors of preterm birth, irrespective of whether they require neonatal intensive care, have (a) increased respiratory symptoms; (b) at least partially reversible airflow obstruction, but with little evidence of eosinophilic inflammation; and (c) abnormal thoracic imaging.

\section{Respiratory symptoms}

Children who survive preterm birth have frequent respiratory symptoms and hospitalisation for respiratory reasons, especially 
in the first decade of life. ${ }^{37} 38$ Even late preterm infants have increased respiratory symptoms and greater likelihood of being given a diagnosis of asthma, ${ }^{39}$ although the exact cause for the symptoms is unclear (see below).

\section{Pulmonary function}

Obstructive spirometry with some acute bronchodilator reversibility is common after premature birth, including in late preterm delivery. ${ }^{40}$ The Avon Longitudinal Study of Parents and Children reported that children born at 33-34 weeks' gestation had impaired childhood lung function comparable to children born 25-32 weeks and who required mechanical ventilation. ${ }^{41}$ This is particularly important because babies born slightly prematurely greatly outnumber those born very prematurely.

Early studies suggested that in the first year of life, far from airway function catching up, it actually worsened over time. ${ }^{42}$ This airway disease is likely different from conventionally understood childhood asthma; although there is evidence of increased airway oxidative stress, ${ }^{32}$ there is no evidence of eosinophilic airway inflammation. ${ }^{43}$ Abnormal parenchymal development may lead to airflow obstruction, ${ }^{45}$ as may airway wall thickening. Space precludes a detailed review of all the literature in this area.

Even, early term delivery (37-38 weeks) has been associated with increased wheezing, although lung function and airway inflammation were not measured, so the relationship to conventionally understood childhood asthma is also unclear in this group. 39

\section{Imaging}

Lung parenchymal abnormalities are common in preterm survivors, especially in those with prolonged oxygen dependency. ${ }^{46}$ It is likely these will be non-progressive, but the extent and severity of some of these changes is concerning.

\section{PRETERM BIRTH AND YOUNG ADULT LUNG HEALTH}

The most persuasive evidence suggests respiratory symptoms are increased and that clinically relevant lung function impairment exists into early adulthood. ${ }^{47} 48$ However, most of these studies were undertaken in subjects at an age where lung growth was still ongoing and some of the findings contrast those reported elsewhere, which have provided some evidence for a more optimistic perspective. ${ }^{20}$ Ultimately the existing literature in adult survivors of preterm birth has been difficult to interpret ${ }^{49}$ for reasons that include small sample size ${ }^{50}$ and the lack of suitable control groups. ${ }^{51}$ These factors may contribute to a clinician 'blind spot'.

\section{Symptoms and quality of life}

Increased respiratory symptoms have been shown to persist into early adulthood. ${ }^{20} 46 \quad 51-55$ Wong and colleagues reported significantly increased respiratory symptoms in a young adult population born at a time prior to the routine use of surfactant and who had all survived moderate to severe BPD. ${ }^{51}$ In a longitudinal evaluation of 21-year-old adults born prematurely, Narang and colleagues identified more respiratory symptoms in the preterm group compared with term controls. ${ }^{20}$ More recently, Gough et al ${ }^{56}$ reported that adult survivors of BPD had significantly more symptoms, more likely to have an asthma diagnosis, be prescribed asthma medication than term controls and also have worse quality of life.

\section{Lung function}

The question whether this tracks through life such that they generally fail to reach peak predicted lung function by adulthood has been debated. It has been suggested that a degree of 'catch-up' or improvement in lung function may occur in survivors of BPD as they reach adolescence. ${ }^{20} 57$ However, this was not evident in a recent cohort study that reported a significant decline in lung function between the ages of 8 and 18 years. ${ }^{48}$ A short report of ex-BPD survivors also suggested a steeper decline. ${ }^{58} \mathrm{~A}$ study of adult survivors of BPD in their third and fourth decade of life confirmed substantial and clinically important airflow obstruction compared with preterm and term controls. ${ }^{56}$ In $87 \%$ of these BPD subjects, airflow obstruction was fixed or only partially reversible (Caskey PhD, QUB, unpublished data). It is uncertain whether impaired lung function is a consequence solely of prematurity or whether BPD is a specific factor. ${ }^{59}$ Halvorsen et $a l^{53}$ reported lung function abnormalities increased with increasing BPD severity. Gibson et $a l^{60}$ recently reported results of a lung function follow-up study of very low birthweight (VLBW) infants both with and without BPD at age 25 years. Adults with VLBW, most of whom were born preterm, had, as expected, more airflow obstruction than terms, but among the VLBW cohort, survivors of BPD had greater reductions in airflow compared with the non-BPD group. Bronchial hyper-responsiveness (BHR) has been reported in preterm survivors; in asthmatics, BHR is associated with a more rapid decline in lung function. Whether this is the case in survivors of prematurity is unclear. ${ }^{61} 62$

There is some evidence for optimism in that, despite the survival of increasingly more premature infants, the $\mathrm{FEV}_{1} \%$ predicted in those who developed lung problems has actually improved over the last three decades. ${ }^{59}$ This may be due to improved medical care including routine use of surfactant, antenatal steroids and gentler mechanical ventilation strategies. There remains concern whether young adults born preterm, having failed to reach optimal lung function, will decline during adulthood with a steeper trajectory than those born at term and whether external factors including the irritant effects of pollution, infection and smoking will have a further detrimental effect on this. The study of Vollsaeter et $a l^{63}$ would suggest tracking, but this needs to be demonstrated in a larger cohort. With respect to other lung physiology, there are few studies. Narang et al $l^{55}$ demonstrated impaired gas transfer in those born preterm compared with term controls. This normalised during exercise.

\section{Structural lung changes}

It is not clear if early preterm lung injury is associated with structural damage to surrounding lung tissue. What evidence there is suggests an association between the extent of radiological abnormality on high-resolution CT (HRCT) scans and the severity of lung function impairment. ${ }^{51} 6465$ Wong and colleagues reported a high prevalence of emphysema in 21 adult survivors of moderate and severe BPD and found the extent of emphysema was inversely related to the $\mathrm{FEV}_{1}$ z-scores. ${ }^{51}$ Aquino $e t a l^{65}$ reported evidence of air trapping and reticular opacities on HRCT scans in the majority of BPD survivors and reported abnormal lung function significantly correlated with air trapping on expiratory scanning. However, these studies lacked a suitable control group. A recent study of adult BPD survivors demonstrated that all had radiological abnormalities on HRCT scans. Significantly more structural lung abnormalities were evident in the adult BPD compared with those preterm non-BPD controls. ${ }^{66}$ 


\section{Exercise capacity}

To date, studies undertaken to characterise exercise capacity in adults born preterm have been relatively small with conflicting findings. ${ }^{4755} 67$ A large population-based national cohort study of male army conscripts reported preterm birth as an independent predictor of reduced exercise capacity. ${ }^{67}$ Narang and colleagues reported no significant difference in exercise capacity between those born preterm and term controls. ${ }^{55}$ Interestingly, those born small for gestational age but not those appropriate for gestational age had reduced cardiac output and carbon monoxide transfer at rest, but these normalised at maximal exercise, suggesting reprogramming of cardiac output rather than heart or lung disease. In contrast, Vrijlandt et $a l^{47}$ reported significantly lower diffusing capacity of the lung for carbon monoxide at rest and 15\% lower workloads in ex preterms compared with term controls. Significant differences in activity levels between groups may have accounted for the lower exercise performance in ex preterms. Clemm and colleagues reported only modest reductions in exercise capacity in adults born extremely preterm compared with term controls, which they attributed to baseline physical activity rather than neonatal factors. ${ }^{68}$ However, all preterm subjects had $\mathrm{FEV}_{1}$ measurements in the normal range, suggesting potential selection bias towards a milder population. Lovering et $a l^{69}$ reported more exercise limitation in ex-preterm adults than terms, which they attributed not only to ventilatory constraints but greater intolerance of dyspnoea and leg discomfort. In a recent study, BPD subjects had significantly lower exercise capacity than non-BPD and term controls despite similar weekly activity levels. Interestingly, $<15 \%$ of the BPD adults were ventilatory limited. ${ }^{70}$

As the number of infants born prematurely has increased globally in the last 30 years, the longitudinal follow-up of larger cohorts of these infants throughout adulthood is required to improve understanding and raise awareness of long-term lung sequelae. $^{71}$

\section{CLINICAL PRESENTATIONS}

There are likely two different groups to consider: those presenting to clinic with respiratory symptoms and those with no symptoms who may have significant lung impairment; this latter group would likely be detected at routine medical screening or at consultation for an intercurrent unrelated illness. Such patients should have their airway function evaluated in detail as above; correct management may reveal to the patient that in fact they were more symptomatic than previously realised. Key is questioning about early life.

\section{APPROPRIATE QUESTIONING IN CLINICS IN THOSE PRESENTING WITH RESPIRATORY SYMPTOMS}

In addition to a full 'adult' clinical respiratory history, specific questions that are relevant in adults who may be presenting with lung disease in part attributable to early-life events include

- birth weight

- gestational age

- time course on a neonatal unit

- the presence of respiratory distress at birth and/or the need for mechanical ventilation or oxygen

- maternal antenatal or postnatal smoking.

However, this in itself poses challenges in that unless the adult is accompanied by their parents they are unlikely to know some of these details. However, they usually know at least if they were very premature, if from no other source than family discussions. While paediatricians are more attuned to ask, have the 'red book' and parents to inform, a more systematic method for recording neonatal data in adult patient records is required. Linked electronic datasets and patient records should address this issue in the future.

Worryingly, our recent British Thoracic Society survey highlighted that few adult respiratory physicians routinely consider early-life factors during patient assessment. ${ }^{8}$ Raising awareness across primary and secondary care will be imperative through structured education opportunities and is one of the purposes of this review. $^{72}$

Diagnostic labels acquired in childhood should always be reconsidered in the adult Chest Clinic, together with reports of impaired physical fitness judged against peers and susceptibility to respiratory infection throughout childhood.

\section{INVESTIGATIONS}

Core pulmonary function tests would include pre-bronchodilator and post-bronchodilator spirometry including flow volume loop. Reversible airflow obstruction may exist without an eosinophilic inflammatory process, which expired nitric oxide (FeNO) measurement may help differentiate. Although pragmatically determining the presence or absence of eosinophilia is a challenge as part of a routine clinical assessment, it would seem justified in these young adults to measure FeNO or induced sputum eosinophils (if available) before committing them to an expensive inhaled corticosteroid therapy with risk of adverse effects.

Through expert consensus, we advocate a low threshold for more detailed physiological testing (total lung volume, gas transfer) when the clinical picture in an adult born premature presents with symptoms and clinical findings atypical for major prevalent respiratory diseases, particularly asthma and COPD. This may also require cross-sectional imaging with CT scanning. However, both approaches require validation before being able to make firm recommendations.

\section{DIFFERENTIAL DIAGNOSES}

Given that the major spirometric manifestation of a preterm birth and BPD in adults appears to be airflow obstruction, the differential diagnosis is primarily that of asthma and COPD, or an 'Asthma COPD Overlap Syndrome'. Ascertaining where airflow obstruction is likely due to preterm birth is important given the potential for misdiagnosis and therefore undertreatment and overtreatment. A diagnosis of COPD generally considered as fixed or partially reversible airflow obstruction following sufficient exposure to noxious particles or gases (in particular, cigarette smoke) may need to be reconsidered in the young adult with little smoking history but fixed airflow obstruction. Likewise, although asthma, at least in its mildest forms, should typically be associated with a significant degree of bronchodilator reversibility, it may not be the correct diagnosis in a preterm-born young adult with exertional wheeze and dyspnoea. Characterising airways disease in adult survivors of preterm birth in terms of extent and nature of airflow obstruction, pattern of any inflammation and presence of airway reactivity is key.

Consideration of other neonatal interventions (eg, subglottic stenosis from repeated intubation or tracheomalacia or bronchomalacia secondary to prolonged mechanical ventilation) that may lead to later symptoms and impaired lung function is fundamental. One study reported that $7 / 13$ adults who had undergone surgery for a patent arterial duct had a left recurrent laryngeal nerve palsy; misdiagnosis as asthma was common, but laryngoscopy correctly diagnosed the abnormality. ${ }^{73}$ This thankfully remains rare. 


\section{MANAGEMENT}

There are no evidence-based or consensus-based guidelines. What is clearly essential is to eschew labels such as 'asthma' and 'COPD' in the preterm survivor; rather the individual components of any lung disease (fixed or variable airflow obstruction, airway inflammation (if any) and hypoxaemia) should be identified and treated on their merits, without extrapolating uncritically from evidence-based management of commoner airway diseases. The standard chronic respiratory disease principles of smoking cessation, annual influenza immunisation, maintaining physical fitness and a general healthy lifestyle should be adhered to. Although individuals born preterm are often risk-averse, ${ }^{74-76}$ smoking is common ${ }^{20}$ and may impact synergistically with other respiratory insults. ${ }^{77}$ Targeted approaches for smoking avoidance or cessation are key and focus on the young age and where smoking may be indoctrinated across generations of one family.

There is no current evidence to advocate widespread use of bronchodilators or inhaled corticosteroids, although a component of variable airflow obstruction may be present. Additional evidence for optimal treatment is required. ${ }^{78}$ They should be introduced on the basis of an individual therapeutic trial and should be discontinued unless there is documented objective improvement. A lack of improvement should not lead to stepwise increments in doses of bronchodilators or particularly inhaled corticosteroids. The failure to correctly diagnose respiratory disease in adults born preterm raises concerns regarding under-appropriate, over-appropriate or inappropriate prescribing. Typically, airflow obstruction, when present, is not associated with asthma-type airway inflammation, ${ }^{43}$ which may or may not respond to asthma therapy. ${ }^{79}$ Therefore, an asthma misdiagnosis in a symptomatic individual is likely to lead to inappropriate stepwise increases in high-dose inhaled and/or oral corticosteroids with the associated deleterious effects of cumulative therapy: bone mineral loss, ${ }^{80}$ increased respiratory infection $^{81}$ and cost. Whether long-term monitoring for (accelerated) decline of lung function is required is uncertain.

\section{TRANSITION OF CARE FROM PAEDIATRICS TO ADULT}

The survivors of preterm birth will reach adult life with airflow obstruction but possibly other comorbidities, including neurodevelopmental with secondary musculoskeletal issues such as joint contractures, visual impairment and possibly pulmonary hypertension, poor growth, bone disease and systemic hypertension.

In childhood, an integrated schools and community therapeutic team will have monitored and treated many of these children; when the child leaves school, none of this is available. Given the lungs continue to develop during childhood, the respiratory issues are unlikely to be majorly symptomatic, often merge with the array of normal childhood respiratory infections and may therefore be overlooked-a 'forgotten generation'.

\section{LIKELY IMPACT ON ADULT SERVICES}

It remains unknown whether all young adults born preterm should have lung function and symptoms assessed. Since introduction into Quality and Outcomes Framework, spirometry has become integrated into primary care for the confirmation of COPD and therefore readily available. However, we currently do not know whether this is the optimal method to determine lung disease of prematurity from other physiological tests. Children and adults born preterm have increased risk of respiratory infections, and the impact on future hospital admissions is likely underestimated. ${ }^{82} 83$

\section{Box 1 Research priorities}

- Need to identify scale of the lung disease, at-risk populations and the moving goalpost effect of ever-better neonatal intensive care.

- We do not fully know the long-term consequences of prematurity, and particularly whether during adulthood there is an accelerated trajectory of decline in symptoms and function.

- Whether there is an active process continuing or whether the lung impairment relates solely to structural/ developmental disruption during the neonatal period.

- Whether screening those born prematurely (or very preterm) allows a window of opportunity to intervene to optimise health status and prevent deterioration.

- Which investigations are optimal for clinically meaningful impaired lung health in those symptomatic.

- Impact on quality of life.

- The potential synergistic adverse effects of other factors such as infections, environmental pollution and smoking.

- Smoking cessation interventions specific for this population.

- Role of pharmacological therapy through well-designed randomised controlled trials.

- Whether annual monitoring is required.

\section{RESEARCH PRIORITIES}

There are large gaps in our understanding of lung disease associated with prematurity that now must be addressed through extensive research (box 1). A real likelihood of longstanding structural and functional limitation into adulthood for those born prematurely highlights the dearth of evidence for identifying and treating this condition. Further, the majority of research in young adults born prematurely that is currently available, by nature, is based on subjects born $20+$ years ago where neonatal care and the size of babies was very different from today; and likely, in 20 years' time, practice will have changed again.

\section{Take home bullet points}

- Increasing numbers of preterm newborns are surviving into adult life.

- They have a unique respiratory disease, comprising airflow obstruction without eosinophilic inflammation, failure of normal lung development, and lung parenchymal destruction.

- Additionally, they may have significant extrapulmonary comorbidities, including neurodevelopmental handicap, retinopathy and bone disease.

- Changing neonatal practices and the survival of ever smaller and more preterm babies mean that the nature of lung disease in survivors may change over time.

- There are no evidence-based guidelines for treatment. Survivors must not be labelled uncritically as 'asthma' or 'COPD' and treated accordingly. Rather it is essential to dissect out in the individual the components of any lung disease, such as fixed airflow obstruction, variable airflow obstruction, airway inflammation (if any) and hypoxaemia, and treat each on its merits. 
However, the most important priorities remain the prevention of preterm delivery (and in this regard, the effects of tobacco legislation have been salutary ${ }^{84}$ ), the optimisation of lung health throughout childhood, and above all, ensuring that adult physicians realise the ongoing burden of respiratory disease and comorbidities in this population. The goalposts are not so much moving as disappearing over the horizon as neonatal intensive care salvages ever smaller babies, and uses ever more innovative treatments, which may, however, cause the baby to pay a heavy price in the long term; and this is the chief future challenge for the next generation of adult chest physicians.

Acknowledgements We thank Mrs Sheila Edwards and Ms Sally Welham, British Thoracic Society, for facilitating roundtable discussions.

Contributors All authors contributed to the planning, drafting and writing of this review article. All authors approved the final version. CEB is the guarantor of the content.

Funding $A B$ was supported by the NIHR Respiratory Disease Biomedical Research Unit at the Royal Brompton and Harefield NHS Foundation Trust and Imperial College London.

Competing interests None declared.

Provenance and peer review Not commissioned; externally peer reviewed.

\section{REFERENCES}

1 Langhoff-Roos J, Kesmodel U, Jacobsson B, et al. Spontaneous preterm delivery in primiparous women at low risk in Denmark: population based study. BMJ 2006;332:937-9

2 Office for National Statistics. Preterm births, preterm births data, press release based on 2005 data. 2005; http://www.ons.gov.uk/ons/publications/ re-reference-tables. html?edition=tcm\%3A77-50818

3 Field DJ, Dorling JS, Manktelow BN, et al. Survival of extremely premature babies in a geographically defined population: prospective cohort study of 1994-9 compared with 2000-5. BMJ 2008:336:1221-3.

4 Draper ES, Zeitlin J, Field DJ, et al. Mortality patterns among very preterm babies: a comparative analysis of two European regions in France and England. Arch Dis Child Fetal Neonatal Ed 2007;92:F356-60.

5 Costeloe KL, Hennessy EM, Haider S, et al. Short term outcomes after extreme preterm birth in England: comparison of two birth cohorts in 1995 and 2006 (the EPICure studies). BMJ 2012;345:e7976.

6 Marlow N, Wolke D, Bracewell MA, et al. Neurologic and developmental disability at six years of age after extremely preterm birth. N Eng/ I Med 2005:352:9-19.

7 Costeloe K, Hennessy E, Gibson AT, et al. The EPICure study: outcomes to discharge from hospital for infants born at the threshold of viability. Pediatrics 2000:106:659-71.

8 Bolton CE, Bush A, Hurst JR, et al. Are early life factors considered when managing respiratory disease? A British Thoracic Society survey of current practice. Thorax 2012;67:1110.

9 Roth-Kleiner M, Post M. Similarities and dissimilarities of branching and septation during lung development. Pediatr Pulmonol 2005;40:113-34.

10 Kimura J, Deutsch GH. Key mechanisms of early lung development. Pediatr Dev Pathol 2007;10:335-47.

11 Maeda Y, Dave V, Whitsett JA. Transcriptional control of lung morphogenesis. Physiol Rev 2007:87:219-44.

12 Morrisey EE, Hogan BL. Preparing for the first breath: genetic and cellular mechanisms in lung development. Dev Cell 2010;18:8-23.

13 Kho AT, Bhattacharya S, Tantisira KG, et al. Transcriptomic analysis of human lung development. Am J Respir Crit Care Med 2010;181:54-63.

14 Quanjer PH, Stanojevic S, Cole TJ, et al. Multi-ethnic reference values for spirometry for the 3-95-yr age range: the global lung function 2012 equations. Eur Respir J 2012;40:1324-43.

15 Stern DA, Morgan WJ, Wright AL, et al. Poor airway function in early infancy and lung function by age 22 years: a non-selective longitudinal cohort study. Lancet 2007;370:758-64.

16 Sears MR, Greene JM, Willan AR, et al. A longitudinal, population-based, cohort study of childhood asthma followed to adulthood. N Engl J Med 2003:349:1414-22

17 Morgan WJ, Stern DA, Sherrill DL, et al. Outcome of asthma and wheezing in the first 6 years of life: follow-up through adolescence. Am I Respir Crit Care Med 2005:172:1253-8.

18 Tai A, Tran $\mathrm{H}$, Roberts $\mathrm{M}$, et al. The association between childhood asthma and adult chronic obstructive pulmonary disease. Thorax 2014;69:805-10.

19 Tai A, Tran H, Roberts M, et al. Outcomes of childhood asthma to the age of 50 years. J Allergy Clin Immunol 2014;133:1572-8 e3.
20 Narang I, Rosenthal M, Cremonesini D, et al. Longitudinal evaluation of airway function 21 years after preterm birth. Am J Respir Crit Care Med 2008;178:74-80.

21 Narayanan M, Owers-Bradley J, Beardsmore CS, et al. Alveolarization continues during childhood and adolescence: new evidence from helium-3 magnetic resonance. Am J Respir Crit Care Med 2012;185:186-91.

22 Hyde DM, Blozis SA, Avdalovic MV, et al. Alveoli increase in number but not size from birth to adulthood in rhesus monkeys. Am I Physiol Lung Cell Mol Physiol 2007:293:L570-9.

23 Fain SB, Altes TA, Panth SR, et al. Detection of age-dependent changes in healthy adult lungs with diffusion-weighted 3He MRI. Acad Radiol 2005;12:1385-93.

24 Northway WH Jr, Rosan RC, Porter DY. Pulmonary disease following respirator therapy of hyaline-membrane disease. Bronchopulmonary dysplasia. N Engl J Med 1967:276:357-68.

25 Shennan AT, Dunn MS, Ohlsson A, et al. Abnormal pulmonary outcomes in premature infants: prediction from oxygen requirement in the neonatal period. Pediatrics 1988;82:527-32

26 Jobe AH, Bancalari E. Bronchopulmonary dysplasia. Am J Respir Crit Care Med 2001;163:1723-9.

27 Jaakkola JJ, Gissler M. Maternal smoking in pregnancy, fetal development, and childhood asthma. Am J Public Health 2004;94:136-40.

28 Romero R, Gotsch F, Pineles B, et al. Inflammation in pregnancy: its roles in reproductive physiology, obstetrical complications, and fetal injury. Nutr Rev 2007;65(12 Pt 2):S194-202.

29 Hilgendorff A, Reiss I, Ehrhardt $\mathrm{H}$, et al. Chronic lung disease in the preterm infant. Lessons learned from animal models. Am J Respir Cell Mol Biol 2014;50:233-45.

30 Penn AL, Rouse RL, Horohov DW, et al. In utero exposure to environmental tobacco smoke potentiates adult responses to allergen in BALB/c mice. Environ Health Perspect 2007:115:548-55

31 Yee M, White RJ, Awad HA, et al. Neonatal hyperoxia causes pulmonary vascular disease and shortens life span in aging mice. Am J Pathol 2011;178:2601-10.

32 Filippone $\mathrm{M}$, Bonetto $\mathrm{G}$, Corradi $\mathrm{M}$, et al. Evidence of unexpected oxidative stress in airways of adolescents born very pre-term. Eur Respir J 2012:40:1253-9.

33 Buczynski BW, Yee M, Paige Lawrence B, et al. Lung development and the host response to influenza $A$ virus are altered by different doses of neonatal oxygen in mice. Am J Physiol Lung Cell Mol Physiol 2012;302:L1078-87.

34 Londhe VA, Sundar IK, Lopez B, et al. Hyperoxia impairs alveolar formation and induces senescence through decreased histone deacetylase activity and up-regulation of p21 in neonatal mouse lung. Pediatr Res 2011;69(5 Pt 1):371-7.

35 Nanduri J, Makarenko V, Reddy VD, et al. Epigenetic regulation of hypoxic sensing disrupts cardiorespiratory homeostasis. Proc Natl Acad Sci USA 2012:109:2515-20.

36 Sartori C, Allemann Y, Trueb L, et al. Augmented vasoreactivity in adult life associated with perinatal vascular insult. Lancet 1999;353:2205-7.

37 Boyle EM, Poulsen G, Field DJ, et al. Effects of gestational age at birth on health outcomes at 3 and 5 years of age: population based cohort study. BMJ 2012;344:e896.

38 Jaakkola JJ, Ahmed P, leromnimon A, et al. Preterm delivery and asthma: a systematic review and meta-analysis. J Allergy Clin Immunol 2006;118:823-30.

39 Harju M, Keski-Nisula L, Georgiadis L, et al. The burden of childhood asthma and late preterm and early term births. J Pediatr 2014;164:295-9 e1.

40 Kotecha SJ, Watkins WJ, Paranjothy S, et al. Effect of late preterm birth on longitudinal lung spirometry in school age children and adolescents. Thorax 2012:67:54-61.

41 Kotecha SJ, Dunstan FD, Kotecha S. Long term respiratory outcomes of late preterm-born infants. Semin Fetal Neonatal Med 2012;17:77-81.

42 Hofhuis W, Huysman MW, van der Wiel EC, et al. Worsening of V'maxFRC in infants with chronic lung disease in the first year of life: a more favorable outcome after high-frequency oscillation ventilation. Am J Respir Crit Care Med 2002;166 (12 Pt 1):1539-43.

43 Baraldi E, Bonetto G, Zacchello $F$, et al. Low exhaled nitric oxide in school-age children with bronchopulmonary dysplasia and airflow limitation. Am J Respir Crit Care Med 2005;171:68-72.

44 Carraro S, Piacentini G, Lusiani M, et al. Exhaled air temperature in children with bronchopulmonary dysplasia. Pediatr Pulmonol 2010;45:1240-5.

45 Filippone M, Carraro S, Baraldi E. The term "asthma" should be avoided in describing the chronic pulmonary disease of prematurity. Eur Respir J 2013:42:1430-1.

46 Aukland SM, Rosendahl K, Owens CM, et al. Neonatal bronchopulmonary dysplasia predicts abnormal pulmonary HRCT scans in long-term survivors of extreme preterm birth. Thorax 2009;64:405-10.

47 Vrijlandt EJ, Gerritsen J, Boezen HM, et al. Lung function and exercise capacity in young adults born prematurely. Am J Respir Crit Care Med 2006;173:890-6.

48 Doyle LW, Faber B, Callanan C, et al. Bronchopulmonary dysplasia in very low birth weight subjects and lung function in late adolescence. Pediatrics 2006:118:108-13.

49 Gough A, Spence D, Linden M, et al. General and respiratory health outcomes in adult survivors of bronchopulmonary dysplasia: a systematic review. Chest. 2012;141:1554-67. 
50 Howling SJ, Northway WH Jr., Hansell DM, et al. Pulmonary sequelae of bronchopulmonary dysplasia survivors: high-resolution CT findings. AJR Am J Roentgenol 2000;174:1323-6.

51 Wong PM, Lees AN, Louw J, et al. Emphysema in young adult survivors of moderate-to-severe bronchopulmonary dysplasia. Eur Respir J 2008;32:321-8.

52 Northway WH Jr, Moss RB, Carlisle KB, et al. Late pulmonary sequelae of bronchopulmonary dysplasia. N Engl J Med 1990;323:1793-9.

53 Halvorsen T, Skadberg BT, Eide GE, et al. Pulmonary outcome in adolescents of extreme preterm birth: a regional cohort study. Acta Paediatr 2004;93:1294-300.

54 Vrijlandt EJ, Gerritsen J, Boezen HM, et al. Gender differences in respiratory symptoms in 19-year-old adults born preterm. Respir Res 2005;6:117.

55 Narang I, Bush A, Rosenthal M. Gas transfer and pulmonary blood flow at rest and during exercise in adults 21 years after preterm birth. Am J Respir Crit Care Med 2009;180:339-45.

56 Gough A, Linden M, Spence D, et al. Impaired lung function and health status in adult survivors of bronchopulmonary dysplasia. Eur Respir J 2014;43:808-16.

57 Bhandari A, Bhandari V. Pathogenesis, pathology and pathophysiology of pulmonary sequelae of bronchopulmonary dysplasia in premature infants. Front Biosci 2003;8: e370-80.

58 Filippone $\mathrm{M}$, Bonetto $\mathrm{G}$, Cherubin $\mathrm{E}$, et al. Childhood course of lung function in survivors of bronchopulmonary dysplasia. JAMA 2009;302:1418-20.

59 Kotecha SJ, Edwards M0, Watkins WJ, et al. Effect of preterm birth on later FEV1: a systematic review and meta-analysis. Thorax 2013;68:760-6

60 Gibson AM, Reddington C, McBride L, et al. Lung function in adult survivors of very low birth weight, with and without bronchopulmonary dysplasia. Pediatr Pulmonol 2014.

61 Grol MH, Gerritsen J, Vonk JM, et al. Risk factors for growth and decline of lung function in asthmatic individuals up to age 42 years. A 30-year follow-up study. Am J Respir Crit Care Med 1999;160:1830-7.

62 Grol MH, Postma DS, Vonk JM, et al. Risk factors from childhood to adulthood for bronchial responsiveness at age 32-42 yr. Am J Respir Crit Care Med. 1999;160: 150-6.

63 Vollsaeter M, Røksund OD, Eide GE, et al. Lung function after preterm birth: Development from mid-childhood to adulthood. Thorax 2013;68:767-76.

64 Wong P, Murray C, Louw J, et al. Adult bronchopulmonary dysplasia: computed tomography pulmonary findings. J Med Imaging Radiat Oncol 2011;55:373-8.

65 Aquino SL, Schechter MS, Chiles C, et al. High-resolution inspiratory and expiratory $\mathrm{CT}$ in older children and adults with bronchopulmonary dysplasia. AJR Am J Roentgenol. 1999;173:963-7.

66 Caskey S, Gillespie S, Clarke J, et al. Structural lung disease in adult survivors of bronchopulmonary dysplasia. Eur Respir J 2013;42(Suppl 57):410.

67 Svedenkrans J, Henckel E, Kowalski J, et al. Long-term impact of preterm birth on exercise capacity in healthy young men: a national population-based cohort study. PLOS ONE 2013;8:e80869.
68 Clemm HH, Vollsaeter M, Roksund OD, et al. Exercise capacity after extremely preterm birth. Development from adolescence to adulthood. Ann Am Thorac Soc 2014;11:537-45.

69 Lovering AT, Elliott JE, Laurie SS, et al. Ventilatory and sensory responses in adult survivors of preterm birth and bronchopulmonary dysplasia with reduced exercise capacity. Ann Am Thorac Soc 2014;11:1528-37.

70 Caskey S, Nicholls P, Riley M, et al. Premature adult lung study: exercise capacity in adult survivors of Bronchopulmonary Dysplasia (BPD). Am J Respir Crit Care Med 2013;187:A3689.

71 Beck S, Wojdyla D, Say L, et al. The worldwide incidence of preterm birth: a systematic review of maternal mortality and morbidity. Bull World Health Organ 2010:88:31-8.

72 Crump C. Medical history taking in adults should include questions about preterm birth. BMJ 2014;349:g4860.

73 Roksund OD, Clemm H, Heimdal JH, et al. Left vocal cord paralysis after extreme preterm birth, a new clinical scenario in adults. Pediatrics 2010;126:e1569-77.

74 Hille ET, Dorrepaal C, Perenboom R, et al. Social lifestyle, risk-taking behavior, and psychopathology in young adults born very preterm or with a very low birthweight. J Pediatr 2008;152:793-800, e1-4.

75 Hack M, Flannery DJ, Schluchter $M$, et al. Outcomes in young adulthood for very-low-birth-weight infants. N Engl J Med 2002;346:149-57.

76 Cooke RW. Health, lifestyle, and quality of life for young adults born very preterm. Arch Dis Child 2004;89:201-6.

77 Guerra S, Stern DA, Zhou M, et al. Combined effects of parental and active smoking on early lung function deficits: a prospective study from birth to age 26 years. Thorax 2013;68:1021-8.

78 Kotecha SJ, Edwards MO, Watkins WJ, et al. Effect of bronchodilators on forced expiratory volume in one second in preterm-born survivors aged 5 and oversystematic review. Neonatology 2015;107:231-40.

79 Chan KN, Silverman M. Increased airway responsiveness in children of low birth weight at school age: effect of topical corticosteroids. Arch Dis Child 1993;69:120-4.

80 Wong CA, Walsh LJ, Smith CJ, et al. Inhaled corticosteroid use and bone-mineral density in patients with asthma. Lancet 2000;355:1399-403.

81 Suissa S. Number needed to treat in COPD: exacerbations versus pneumonias. Thorax 2013;68:540-3.

82 Walter EC, Ehlenbach WJ, Hotchkin DL, et al. Low birth weight and respiratory disease in adulthood: a population-based case-control study. Am J Respir Crit Care Med 2009;180:176-80.

83 Walter EC, Koepsell TD, Chien JW. Low birth weight and respiratory hospitalizations in adolescence. Pediatr Pulmonol 2011;46:473-82.

84 Cox B, Martens E, Nemery B, et al. Impact of a stepwise introduction of smoke-free legislation on the rate of preterm births: analysis of routinely collected birth data. BMJ 2013;346:f441. 